\title{
Peningkatan Kemampuan Motorik Halus melalui Kegiatan Menggambar Anak Kelompok A di TKN Pekunden 1
}

\author{
Peni Pratiwi
}

TKN Pekunden 1 Kota Blitar, Indonesia

Email: penipratiwi1967@gmail.com

\section{Tersedia Online di}

http://www.jurnal.unublitar.ac.id/in dex.php/briliant

\begin{tabular}{l}
\hline Sejarah Artikel \\
\hline Diterima pada 11 November 2019 \\
Disetujui pada 27 November 2019 \\
Dipublikasikan pada 30 November \\
2019 Hal. 521-527
\end{tabular}

\section{Kata Kunci:}

Peningkatan, pengembangan motorik, menggambar, efektivitas

DOI:

http://dx.doi.org/10.28926/briliant. v3i4.410

\begin{abstract}
Abstrak: Pengembangan motorik, kognitif, psikomotorik dan efektivitas anak perlu distimulus sejak dini. Penerapan tersebut dapat dilihat dari kegiatan anak dalam menggambar. Tujuan penelitian ini adalah untuk memberikan stimulasi motorik pada anak melalui kegiatan pembelajaran menggambar. Metode yang digunakan yaitu Pendidikan Tindakan Kelas (PTK). Prosedur yang digunakan terdapat dua siklus. yang meliputi perencanaan, pelaksanaan, observasi dan refleksi. Hasil yaitu bahwa tahapantahapan pembelajaran menggambar pada anak bahwa pada siklus I penilaian kegiatan pembelajaran menggambar tidak terdapat hasil yang signifikan dengan nilai rata-rata kurang dari indikator bintang 2. Berbeda pada kegiatan pembelajaran pada siklus II yang memiliki hasil yang signifikan dengan nilai rata bintang 3 dan bintang 4 (tuntas).
\end{abstract}

\section{PENDAHULUAN}

Berdasarkan pengamatan terhadap pengembangan kemampuan dasar kognitif di kelas ditemukan adanya kesulitan anak terhadap kegiatan menggambar bebas. Kesulitan ini ditandai dengan anak yang selalu berkomentar jika hari ini kegiatan menggambar bebas. Selain itu hasil kegiatan anak tidak optimal dan baik, seringkali guru menemukan hasil menggambar anak dengan bentuk yang sama dengan teman sebangkunya. Hal ini terjadi karena anak belum mempunyai referensi dan contoh gambar yang menarik anak saat kegiatan berlangsung atau bisa juga metode yang dipergunakan guru dalam kegiatan pembelajaran kurang tepat. Sehingga menyebabkan siswa kurang aktif yaitu cenderung ramai dan bosan dalam mengerjakan tugas dari guru. Apalagi setelah melihat kegiatan yang diberikan oleh guru berupa menggambar bebas anak sudah merasa kegiatan ini tidak menarik sehingga anak semaunya sendiri dalam mengerjakan tugasnya.

Guru yang kurang pandai dalam mengkondisikan kelas juga menjadi salah satu sebab siswa tidak aktif dalam kegiatan pembelajaran. Hal lain yang mungkin terjadi yaitu guru kurang melakukan supervisi di kelasnya pada anak ketika ada kegiatan menggambar bebas. Guru selalu sibuk sendiri dan anak ragu untuk mengerjakan tugas. 
Di Taman Kanak-kanan Nasional (TKN) Pembina Kecamatan Kepanjenkidul Kota Blitar siswa kelompok A2 kurang berminat terhadap kegiatan menggambar bebas. Hal ini bisa diketahui ketika ada kegiatan menggambar ada siswa yang langsung menangis, mengeluh dan bahkan ada yang langsung berteriak "saya tidak bisa". Hal ini yang mendorong penulis yang juga guru melakukan penelitian perbaikan untuk meningkatkan kemampuan kognitif anak melalui kegiatan menggambar bebas. Oleh karena itu dalam penelitian ini kami akan menyampaikan berbagai pemecahan-pemecahan agar bermanfaat bagi guru yang memiliki masalah yang sama agar dapat teratasi dengan baik.

\section{METODE}

Prosedur penelitian ini menggunakan dua siklus yaitu:

\section{Siklus I}

1. Perencanaan Perbaikan

Pada tahap perencanaan ini yang dilaksanakan peneliti adalah:

a. Menganalisis kurikulum untuk mengetahui kompetensi dasar yang akan disampaikan kepada siswa.

b. Membuat rancangan 1 Siklus dan RKH 1- 5 yang dapat dilihat pada lampiran.

c. Mempersiapkan media untuk pembelajaran motorik halus dalam kegiatan menggambar.

d. Mempersiapkan lembar observasi

2. Pelaksanaan Perbaikan

Tindakan pembelajaran dilakukan secara berkelompok

a. Guru bercerita tentang ciri-ciri sayuran

b. Mengajak anak lebih aktif

c. Guru memperlihatkan bermacam-macam media gambar sayuran yang sering dimakan sehari-hari.

d. Guru membagikan buku gambar dan meminta anak untuk menggambar sayuran.

e. Sebelum kegiatan dimulai, guru memberi contoh gambar yang mudah

f. Anak menggambar dengan bebas.

3. Observasi

Pada tahap ini peneliti mengamati anak selama mengikuti kegiatan menggambar. Peneliti membuat lembar observasi tentang proses dan hasil dari kegiatan dan mengisi format observasi sebagaimana pada Tabel 1. Pada saat proses menggambar peneliti melakukan pengamatan tentang ketertarikan anak pada kegiatan menggambar.

Tabel 1. Lembar Pedoman Penilaian Observasi

\begin{tabular}{|c|c|c|c|c|}
\hline No & Nama Anak & $\begin{array}{c}\text { Nilai sebelum } \\
\text { siklus }\end{array}$ & $\begin{array}{c}\text { Nilai } \\
\text { siklus }\end{array}$ & Keterangan \\
\hline 1 & & & & \\
\hline 2 & & & & \\
\hline $\mathrm{dst}$ & & & & \\
\hline
\end{tabular}




\section{Keterangan :}

$$
\begin{aligned}
& \star \star=\text { Belum tuntas } \\
& \star \star \star=\text { Tuntas }
\end{aligned}
$$

4. Refleksi

a. Kekuatan dan Kelemahan Tindakan Perbaikan :

1) Dalam pembelajaran ini kegiatan menggambar lebih terfokus

2) Dalam tindakan perbaikan diterapkan akan mendapat hasil yang optimal

3) Anak akan tertarik dan senang menggambar setelah ada motivasi dari guru

b. Kekuatan dan Kelemahan dalam Merancang dan Melakukan Tindakan Perbaikan :

1) Dengan merancang suatu tindakan perbaikan guru akan lebih siap dalam suatu pembelajaran yang kurang berhasil

2) Bila rancangan tindakan perbaikan tidak berhasil akan menggunakan rancangan yang lain yang sudah disiapkan.

\section{Siklus II}

1. Perencanaan Perbaikan

Pada tahap perencanaan ini yang dilakukan peneliti adalah:

a. Menganalisis kurikulum untuk mengetahui kompetensi dasar yang akan disampaikan kepada siswa.

b. Membuat rancangan 1 Siklus RKH yang dapat dilihat pada lampiran

c. Mempersiapkan media untuk pembelajaran motorik halus yaitu menggambar

d. Mempersiapkan lembar observasi

2. Pelaksanaan Perbaikan

Tindakan pembelajaran dilakukan secara berkelompok:

a. Guru membagikan buku gambar atau alat untuk menggambar

b. Guru Mengkomunikasikan tujuan kegiatan pembelajaran dan pemanfaatan kegiatan menggambar kepada siswa.

c. Tanya jawab untuk menggali pengetahuan dan perbaikan anak tentang penggunaan media.

d. Guru memberi kesempatan kepada anak untuk menggambar.

3. Observasi

Pada tahap ini peneliti mengamati anak selama mengikuti kegitatan menggambar. Peneliti membuat lembar observasi tentang proses dan hasil dari kegiatan dan mengisi format observasi sebagaimana Tabel 1.

5. Refleksi

a. Kekuatan dan Kelemahan Tindakan Perbaikan :

1. Dalam pembelajaran ini kegiatan menggambar lebih terfokus

2. Dalam tindakan perbaikan diterapkan akan mendapat hasil yang optimal 
3. Anak akan tertarik dan senang menggambar setelah ada motivasi dari guru

b. Kekuatan dan Kelemahan dalam Merancang dan Melakukan Tindakan Perbaikan :

1. Dengan merancang suatu tindakan perbaikan guru akan lebih siap dalam suatu pembelajaran yang kurang berhasil

2. Dalam rancangan tindakan perbaikan ini sudah tampak keberhasilan dan perubahan dari Siklus sebelumnya. Sehinga tindakan perbaikan sudah selesai pada Siklus II

\section{HASIL}

Penelitian Tindakan Kelas (PTK) di TKN Pembina Kecamatan Kepanjenkidul yang dilakukan tanggal 31 Oktober - 4 Nopember 2011 pada siklus 1 dan tanggal 5-11 Nopember 2011 pada siklus II diharapkan dapat meningkatkan kemampuan kognitif pada kelompok A melalui kegiatan menggambar. Adapun Hasil Penelitian melalui siklus dapat diinterprestasikan sebagai berikut:

\section{Siklus 1}

1. Perencanaan

Siklus I dilaksanakan pada tanggal 31 Oktober - 4 Nopember 2011. peneliti melakukan tindakan sebagai berikut:

Guru membuat Rencana Kegiatan Harian yang materi-materi pokok (K.18) menggambar baju dari bentuk lingkaran dan segi empat. Guru mempersiapkan media gambar-gambar, bahan pembelajaran dan alat penilaian berupa lembar.

Tabel 2. Hasil penilaian kemampuan anak pada siklus I

\begin{tabular}{|c|l|c|c|c|}
\hline No & \multicolumn{1}{|c|}{ Nama Anak } & $\begin{array}{c}\text { Nilai Sebelum } \\
\text { Siklus }\end{array}$ & Nilai Siklus I & Keterangan \\
\hline 1 & Fafian Bagus Aditama & $\star \star$ & $\star \star$ & Meningkat \\
\hline 2 & Ananda Ilmi Budi Lestari & $\star$ & $\star \star$ & Meningkat \\
\hline 3 & Diah Ayu Kusumaningrum & $\star \star$ & $\star \star$ & Meningkat \\
\hline 4 & Denta Aulia Salsabela & $\star \star$ & $\star \star$ & Meningkat \\
\hline 5 & Flowrensia Safira & $\star$ & $\star \star$ & Meningkat \\
\hline 6 & Aditiya Prisanto Putra & $\star \star$ & $\star \star$ & Meningkat \\
\hline 7 & Valerian Rehan Wijaya & $\star$ & $\star \star$ & Meningkat \\
\hline 8 & Aditya & $\star$ & $\star \star$ & Meningkat \\
\hline 9 & Sela Nurmala Putri & $\star \star$ & $\star \star$ & Meningkat \\
\hline 10 & Zeruna Sachi Setiono & $\star \star$ & $\star \star$ & Meningkat \\
\hline 11 & Hibban Dava Anafi & $\star$ & $\star$ & Meningkat \\
\hline 12 & Andika Santosa & $\star$ & $\star \star$ & Meningkat \\
\hline 13 & Melisa Ramadani & $\star \star$ & Meningkat \\
\hline 14 & Bagus Fawas & $\star$ & & Meningkat \\
\hline
\end{tabular}




\begin{tabular}{|l|l|c|c|c|}
\hline 15 & Evan Pandia Khalfani & $\star$ & $\star \star$ & Meningkat \\
\hline
\end{tabular}

2. Tindakan

Pada tahap ini yang dilakukan peneliti adalah (1) mengatur tempat duduk siswa dengan cara berkelompok menjadi 3 kelompok, (2) apersepsi tentang sub tema dari tema kebutuhankku, (3) guru memberikan penjelasan tentang kegiatan yang akan dilakukan dan memberikan penjelasan tentang tata cara melaksanakan kegiatan salah satunya adalah kegiatan menggambar, (4) guru memberi kesempatan kepada ketua kelompok untuk menulis salah satu kegiatan terlebih dahulu, (5) guru mengajak anak memulai kegiatan dan setelah selesai anak boleh pindah ke kegiatan lain, (6) guru melakukan pengamatan.

3. Pengamatan

Pada tahap ini peneliti melakukan pengamatan dan penilaian pada ana melalui lembar observasi untuk mengetahui perkembangan anak. Hasil pada tahap ini menunjukkan bahwa banyak siswa merasa senang dengan hasil yang memuaskan pada setiap kegiatannya.

\section{Siklus II}

1. Perencanaan

Siklus I dilaksanakan pada tanggal 7 Nopember - 11 Nopember 2011. Pada siklus II ini dilakukan cara yaitu guru membuat rencana kegiatan harian yang materi-materi pokok (K.18) menggambar baju dari bentuk lingkaran dan segi empat. Guru mempersiapkan media gambar-gambar, bahan pembelajaran dan alat penilaian berupa lembar sebagai berikut:

2. Tindakan

Pada tahap ini yang dilakukan peneliti adalah (1) mengatur tempat duduk siswa dengan cara berkelompok menjadi 3 kelompok, (2) apersepsi tentang sub tema dari tema kebutuhankku, (3) guru memberikan penjelasan tentang kegiatan yang akan dilakukan dan memberikan penjelasan tentang tata cara melaksanakan kegiatan salah satunya adalah kegiatan menggambar, (4) guru memberi kesempatan kepada ketua kelompok untuk menulis salah satu kegiatan terlebih dahulu, (5) guru mengajak anak memulai kegiatan dan setelah selesai anak boleh pindah ke kegiatan lain, (6) guru melakukan pengamatan.

\section{Pengamatan}

Pada tahap ini peneliti melakukan pengamatan dan penilaian pada ana melalui lembar observasi untuk mengetahui perkembangan anak. Hasil pada tahap ini menunjukkan bahwa banyak siswa merasa senang dengan hasil yang memuaskan pada setiap kegiatannya.

Tabel 2. Hasil penilaian kemampuan anak pada siklus II

\begin{tabular}{|c|l|c|c|c|}
\hline No & \multicolumn{1}{|c|}{ Nama Anak } & Siklus 1 & Siklus 2 & Keterangan \\
\hline 1 & Fafian Bagus Aditama & $\star \star \star$ & $\star \star \star$ & Meningkat \\
\hline 2 & Ananda Ilmi Budi Lestari & $\star \star$ & $\star \star \star$ & Meningkat \\
\hline
\end{tabular}




\begin{tabular}{|c|l|c|c|c|}
\hline 3 & Diah Ayu Kusumaningrum & $\star \star \star$ & $\star \star \star$ & Meningkat \\
\hline 4 & Denta Aulia Salsabela & $\star \star$ & $\star \star \star$ & Meningkat \\
\hline 5 & Flowrensia Safira & $\star \star$ & $\star \star \star$ & Meningkat \\
\hline 6 & Aditiya Prisanto Putra & $\star \star \star$ & $\star \star \star \star$ & Meningkat \\
\hline 7 & Valerian Rehan Wijaya & $\star \star$ & $\star \star \star$ & Meningkat \\
\hline 8 & Aditya & $\star \star$ & $\star \star \star$ & Meningkat \\
\hline 9 & Sela Nurmala Putri & $\star \star \star$ & $\star \star \star$ & Meningkat \\
\hline 10 & Zeruna Sachi Setiono & $\star \star \star$ & $\star \star \star$ & Meningkat \\
\hline 11 & Hibban Dava Anafi & $\star \star \star$ & $\star \star \star$ & Meningkat \\
\hline 12 & Andika Santosa & $\star \star$ & $\star \star \star$ & Meningkat \\
\hline 13 & Melisa Ramadani & $\star \star \star$ & $\star \star \star \star$ & Meningkat \\
\hline 14 & Bagus Fawas & $\star \star$ & $\star \star \star$ & Meningkat \\
\hline 15 & Evan Pandia Khalfani & $\star \star$ & $\star \star \star$ & Meningkat \\
\hline
\end{tabular}

Keterangan Pada Siklus 1 dan Siklus 2

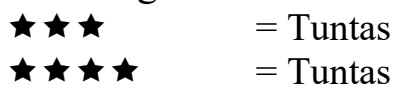

\section{PEMBAHASAN}

Hasil analisa pengelolaan data dari teman sejawat dan kepala TK hasilnya menggembirakan tetapi belum menunjukkan kemajuan yang pesat oleh siswa. Hal ini dketahui dari hasil lembar observasi yang mengalami peningkatan tidak terlalu signifikan. Padas siklus I ini menjadi bahan evaluasi bagi seorang agar dalam penerapan model dan pendidikan. Ada beberapa hal yang perlu untuk dilakukan agar anak mendapatkan hasil yang baik dan optimal dalam mencapai prestasi anak yang lebih baik (Masrayani, Suhartono, \& Muchtar, 2013). Salah satunya melalui perbaikan dalam pembelajaran. Metode yang dapat digunakan dalam pendidikan anak yaitu dengan menerapkan model pembelajaran yang kreatif dan kondusif (Asmadawati, 2014). Selain kreativitas pembelajaran juga dibutuhkan perencanaan yang lebih terencana dengan sentuhan inovasi dalam pembelajaran anak berkembang dan optimal (Sumanto, 2018).

Berdasarkan hasil evaluasi dari kegiatan pembelajaran pada siklus II terdapat peningkatan yang sangat memuaskan. Hal ini dibuktikan dengan adanya peningkatan keaktifan siswa dalam pelaksanaan pembelajaran. Keberhasilan lainnya bahwa anak sangat antusias dalam mengikuti pembelajaran. Hal ini dapat dilihat dari hasil pengamatan oleh teman sejawat TK bahwa anak hampir seluruhnya mendapat kisaran penilaian antara bintang $3(\star \star \star)$ dan bingant 4 $(\star \star \star \star)$. Keberhasilan ini merupakan keberhasilan dalam pendidikan yang terencana. Penerapana model pendidikan sangat berpengaruh terhadap tingkat keberhasilan siswa (DePorter, Reardon, \& Singer-Nourie, 2010). Ketercapaian prestasi anak merupakan salah satu peranan dari pemberian motivasi dan inovasi dalam model pendidikan, sehingga sangat berpengaruh nyata untuk mencapai prestasi anak (Cahyono, 2011). 


\section{KESIMPULAN}

Pelaksanaan kegiatan sesuai indikator maka kemampuan seni anak melalui kegiatan menggambar dapat dikembangkan secara maksimal. Latihan dan kegiatan menggambar pada setiap hari maka anak mudah memperoleh hasil yang bagus. Kegiatan menggambar dapat menumbuhkan rasa seni pada anak dan kemampuan dasar seni yang harus dikembangkan.

\section{DAFTAR RUJUKAN}

Asmadawati, A. (2014). Menciptakan Pembelajaran Kreative dan Kondusif. Paper presented at the FORUM PAEDAGOGIK Jurnal Pendidikan Agama Islam.

Cahyono, F. (2011). Peningkatan Kemampuan Berkarya Seni Grafis Cetak Tinggi Teknik Hardboardcut Melalui Pendekatan Ekspresi-Kreatif Siswa Kelas VIII A SMP Negeri 25 Malang: Malang: Universitas Negeri Malang.

DePorter, B., Reardon, M., \& Singer-Nourie, S. (2010). Quantum teaching: mempraktikkan quantum learning di ruang-ruang kelas: Kaifa.

Masrayani, M., Suhartono, S., \& Muchtar, S. (2013). Meningkatkan Kreativitas Seni Anak Melalui Latihan Membuat Sepeda Dari Pipet di Kelompok B Paud Bunda Delima Desa Darat Sawah Kecamatan Seginim Kabupaten Bengkulu Selatan. Universitas Bengkulu.

Sumanto, S. (2018). Seni Keterampilan Anak untuk Meningkatkan Kualitas Pembelajaran bagi Guru. Abdimas Pedagogi: Jurnal Ilmiah Pengabdian kepada Masyarakat, 1(2), 164-170. 